\title{
Struggling for Space and Finding My Place: An Interactionist Perspective on Everyday Use of Biomedical Information
}

\author{
Christine T. Wolf \\ School of Information \& Computer Sciences, University of California-Irvine, Irvine, CA 92697. \\ E-mail:wolfct@uci.edu \\ Tiffany C. Veinot \\ School of Information, University of Michigan, Ann Arbor, MI 48109-1285. E-mail: tveinot@umich.edu
}

Information use intrigues information behavior researchers, though many have struggled with how to conceptualize and study this phenomenon. Some work suggests that information may have social uses, hinting that information use is more complicated than previous frameworks suggest. Therefore, we use a micro-sociological, symbolic interactionist approach to examine the use of one type of information-biomedical information-in the everyday life interactions of chronic illness patients and their families. Based on a grounded theory analysis of 60 semi-structured interviews (30 individual patient interviews and $\mathbf{3 0}$ family group interviews) and observations within the family group interviews, we identify 4 categories of information use: (a) knowing my body; (b) mapping the social terrain; (c) asserting autonomy; and (d) puffing myself up. Extending previous research, the findings demonstrate use of biomedical information in interactions that construct a valued self for the patient: a person who holds authority, and who is unique and cared for. In so doing, we contribute novel insights regarding the use of information to manage social emotions such as shame, and to construct embodied knowledge that is mobilized in action to address disease-related challenges. We thus offer an expanded conceptualization of information use that provides new directions for research and practice.

\section{Introduction}

How people use information is an issue that intrigues those who study information behavior. Yet, from the earliest investigations, information scientists have struggled with the challenges of conceptualizing and studying information use

Received June 24, 2013; revised November 4, 2013; accepted November 5, 2013

(C) 2014 ASIS\&T • Published online 15 May 2014 in Wiley Online Library (wileyonlinelibrary.com). DOI: 10.1002/asi.23178
(Dervin \& Nilan, 1986; Paisley, 1968). The most salient challenge is defining what we mean when we say "use." Hewins (1990) points out that information needs and information use are often conflated. Indeed, reviews of the information behavior literature highlight work exploring information needs and seeking, but rarely information use (Case, 2006; Fisher \& Julien, 2009). Work that does address information use often explores the question by analyzing what information sources are consulted in the informationseeking process (Lin \& Garvey, 1972) or what sources are cited in academic articles (Borgman \& Furner, 2002). In both cases, the sources themselves serve as an indicator of use, whereas the particular processes of use remain elusive. Notably, however, some recent work suggests that information may have personal (Savolainen, 2006, 2009) and social (Anderson, 2007; Lloyd, Bonner, \& Dawson-Rose, 2013; McKenzie, 2004; Sundin, 2003; Tuominen \& Savolainen, 1997; Tuominen, Savolainen, \& Talja, 2005) uses, hinting that information use may be more complex than previously suspected.

We ask how people with chronic conditions use biomedical information in their everyday family lives and examine this question through participant accounts of interactions and through our observations of family interactions in group interviews. Health is a rich field in which to examine information use, because those with chronic health conditions encounter biomedical information in a deep way: their lives are saturated with this type of information and their experiences embed it in their everyday, social lives. Thus, their experiences offer us a vivid look at how a distinct type of information is used in the context of everyday life. Moreover, the biomedical field also offers an opportunity to further examine the role of information use in the process of everyday authority taking, an issue that Tuominen and 
Savolainen (1997) highlight in their prior work. We focus primarily on information use in families, because families are one of the key institutions in contemporary society (Newman \& Grauerholz, 2002; Scott, Treas, \& Richards, 2004), and a central site of everyday life. Moreover, the importance of family support in issues of health, particularly in coping with illness, is well established (Cutrona \& Gardner, 2006; Elliott \& Shewchuk, 2004; Sullivan \& Davila, 2010). Family relationships also offer a valuable setting in which to examine collaborative information behavior, although previous work in the area has focused more on information acquisition than information use (e.g., Veinot, 2009).

Empirical findings from our research suggest that, following Tuominen and Savolainen (1997), there is value in expanding our conceptualization of information use to include social uses. We extend the dialogue further in our novel application of a symbolic interactionist perspective to the investigation of information use. In doing so, we contribute theoretical insight to our field's conceptualization of information use. Symbolic interactionism (SI), with its roots in the pragmatic philosophy of George Herbert Mead (Shalin, 1986) and the Chicago school of sociology, has been one of the dominant micro-sociological paradigms since the early 20th century (Veinot \& Williams, 2012). It is a constructivist paradigm that views the human experience as one of constant, iterative negotiation and interpretation of the world, achieved through interaction; as such, interaction is seen as the key meaning-making process in human life (Charon, 2010). Although Chatman (1999) drew inspiration from SI, it has gained limited notice in the information studies field. Nevertheless, we contend that SI is a framework that is well suited to information studies, given its central focus on information, which the SI tradition conceptualizes as "meaning" (Veinot \& Williams, 2012). We contribute a novel symbolic interactionist theoretical perspective to the field of information behavior in the process of investigating the following research question:

How do patients with chronic conditions use biomedical information in everyday life interactions with the self and with their family members?

\section{Literature Review}

Information scientists have investigated information use from multiple perspectives, using an array of definitions. Kari (2010) notes that some have defined information use to include virtually any human-information interaction. Others have focused on information needs (Dervin \& Nilan, 1986; Hewins, 1990) and information seeking (Case, 2006; Fisher \& Julien, 2009) rather than use per se, whereas some have conceptualized information use as a question of what sources are consulted (Lin \& Garvey, 1972) or cited (Borgman \& Furner, 2002). Choo (1996) explored information use from an organizational perspective, looking at how organizations use information to make sense of environ- ments, generate new knowledge, and make decisions. Savolainen $(2006,2009)$ explored information use as understood through Dervin's (1998) sense-making model of information seeking. This approach highlighted the potential personal uses of information (e.g., cognitive and affective) to solve problems by bridging gaps in one's experience. Tuominen and Savolainen (1997) have looked at potential interpersonal uses of information, specifically how information is used to support claims in social discourse. This work suggests that information may indeed have diverse uses, but the particular processes of how information is used in everyday life remain largely unexplored, particularly from a sociological perspective.

Health behavior literature has also explored the question of information use. This work usually conceptualizes information use as behavioral effects-are patients using information to change their health behavior? (Rimal, 2000; Sheeran, 2002; Sligo \& Jameson, 2000). The approach is limited because it misses the potential uses of information that go beyond the health behavior change process. Some work has questioned this narrow approach (Meadowbrooke, Veinot, Loveluck, Hickok, \& Bauermeister, 2014). For example, some have explored more diverse personal uses of health information, particularly to meet emotional needs (Lee, Hwang, Hawkins, \& Pingree, 2008; Nahl, 2007; Veinot, 2010). But health behavior research accords little attention to social uses of information. Although some work has examined the social means by which patients seek and acquire information, for example, by exploring health information seeking via social media outlets (Frost \& Massagli, 2008; Greene, Choudhry, Kilabuk, \& Shrank, 2011), health information exchange in the clinical setting (McKenzie, 2004, 2010; Rivano-Eckerdal, 2011a,b, 2012), or interactive (Veinot, 2009) and mediated (Wathen, Wyatt, \& Harris, 2008) forms of information acquisition in everyday life, the social uses of information in everyday life interactions remain uncharted in this body of literature.

The communication studies literature has also investigated the question of information use in the domain of health and biomedicine. This work usually adopts a macro perspective: mass communications, rather than interpersonal communications, are often analyzed. This approach attempts to deal with the "problem" of a broad gap in scientific knowledge by advocating contextually appropriate mass communication interventions (Gregory \& Miller, 1998; Mikulak, 2011). These approaches are premised on the idea that if institutions deliver information in more contextually appropriate ways, the public will be more likely to understand it, and in turn, make better decisions and have more informed opinions and attitudes (Gregory \& Miller, 1998; Allum, Strugis, Tabourazi, \& Brunton-Smith, 2008). Some literature in this area employs a social representation framework (Moscovici, 2000) drawn from the field of social cognition. Social representation research examines the collective basis of lay people's understandings and reworkings of biomedical concepts. This framework has been applied extensively to the area of health risk communication (e.g., Joffe, 2003). It has 
also been explored in contexts such as health psychology (Joffe, 2002), including specific domains such as public attitudes about MRSA (Washer \& Joffe, 2006) and organ donation (Morgan, 2009). This approach is limited in that rather than exploring information use as simultaneous processes of interactions between people and institutions, the public is largely viewed as an empty vessel waiting to be filled with institutional knowledge or as needing to have their misconceptions corrected.

Some have also looked at information use from a sociology of health perspective. This work typically explores lay health knowledge or expertise, the localized information gleaned from a patient's individual experience, and its potential use in clinical practice. For instance, lay health knowledge has been explored in areas where clinical knowledge is uncertain or ambiguous, such as repetitive-stress injuries (RSI) (Arksey, 1998) and genetic metabolic disorders (Lambert \& Rose, 1996). This work has also considered lay health knowledge as it is aggregated in support groups or other settings (Arksey, 1998). This approach, however, broadly sees lay knowledge as being absorbed into and used by clinical practice and does not necessarily explore the potential social uses of lay health information by patients in everyday life interactions.

In sum, many disciplines have examined the phenomenon of information use, but existing perspectives are incomplete in that they miss the potential for use of (biomedical) information in everyday interactions. However, a small body of work, (Anderson, 2007; Choo, 1996; Lloyd et al., 2013; McKenzie, 2004; Sundin, 2003; Tuominen \& Savolainen, 1997; Tuominen et al., 2005) hints that information may indeed have more dynamic, social uses than have been previously described. Exploring further how information is deployed in everyday life interactions can help to provide a more complete picture of the role of information in contemporary life.

\section{Theoretical Frameworks}

Drawing from SI, our analysis focuses on the "interaction" as the key meaning-making process in the human experience and adopts the following frameworks as "sensitizing concepts" (Blumer, 1969). Interaction, is distinguished from action, in that the former implies joint action (A acts on B while $B$ also acts on $A$ ), whereas the latter implies singular action (A acts on B only) (McCall, 2003). Thus, from an SI perspective, we not only construct the world around us through this interactional process, but we also construct our self in this process as well. Self is a social object, simultaneously an object and an actor (Charon, 2010; Weigert \& Gecas, 2003). Self is distinct from identity: identity is the meaning attributed to the self (Charon, 2010; Vryan, Adler, \& Adler, 2003), usually achieved through the use of labels, or symbols of identity. In SI, meaning is a hypothesis or idea about the world, which emerges through the interpretive process of indication and response in interactions (Hewitt, 2003). An indication, in this sense, is a message directed toward the self, highlighting, selecting, and announcing what is significant in the emergent interaction (Blumer, 1969; Hewitt, 2003). In SI, self-indication is a central process of thought, as well as the process through which human actions are formed (Blumer \& Morrione, 2004, p. 75).

Interactions can be with other people, but they can also be with symbols, objects, and the self. Therefore, we use "interaction" to mean both interactions with the self and interpersonal interactions with others and thus explore biomedical information use in both types of interactions. Building on Mead's (1938) early identification of language as a "significant symbol" that elicits a similar response in both the producer and recipient via shared meaning, we extend this view to include biomedical information as a kind of "significant symbol" that behaves similarly.

As is the case in much information theory (e.g., Cornelius, 2002), an SI framework supports a distinction between information and knowledge (Goff, 1980). In SI theory, information is a meaning (Veinot \& Williams, 2012) that emerges in interaction. Because meaning is located in the response it elicits, information is also an "experience" (Mead, 1938, p. 54). This experience includes humans' direction of attention to stimuli in the environment, their associated self-indication regarding the significance of those stimuli, and their subsequent internalization of existing meanings as "attitudes," or "tendencies to act" towards those stimuli (Blumer \& Morrione, 2004; Goff, 1980; Mead, 1938). In this research, we define "biomedical information" as those meanings that are specifically generated by, or traceable to, biomedical institutions, such as universities, laboratories, hospitals, and health care professions.

Drawing on SI's roots in pragmatic philosophy, we characterize knowledge as a feature of social action; in Mead's terms, knowing "is inside the process of conduct" (Mead and Morris, 1940, p. 401). Knowledge is a "process" of "adjustment" (Mead \& Moore, 1949, p. 350) that involves the "active construction and reorganization of attitudes" in response to "problematics" that arise in human experience (Goff, 1980, p. 84). As such, knowledge is "the activity of establishing what and how to do something" (McCarthy, 1992, p. 108), of hypothesis generation and testing (Mead, 1938) and thereby of "organiz[ing] the field of action so that an inhibited action can proceed" (McKinney, 1955, p.149).

This article also uses the information science-based conception of relevance, which we take to mean the relationship between information and the user (Huang \& Soergel, 2013; Saracevic, 2007). We see relevance as a relationship manifested through the process of interaction between the user and information: it is context-specific, fluid, and driven by the user. As Saracevic (2007) says: "Relevance is a human ... notion and human notions are complex, even messy." (p. 1918). We agree. We also understand experience to have an effect on relevance. The more experience one has with a particular topic, the easier it is for one to determine relevancy (Saracevic, 2007).

Wilson's (1983) theory of cognitive authority also informs our work. When users do not have first-hand 
experience, they rely on their cognitive authorities to discern information credibility; a cognitive authority influences the user's thinking (Wilson, 1983). Because of our interactionist approach, our use of the concept of cognitive authority differs from Wilson's in one key way: rather than exploring authority from an approach of what is listened to (Wilson's approach to cognitive authority) or what must be listened to (Wilson's definition of administrative authority), our work examines claims that one should be listened to. We see this type of claim as an interactional appropriation of cognitive authority. Published research can be a symbol used in the process of claiming authority in health care (Sundin, 2003), as can invocation of biomedical institutions as the source of specific information. Authority claims can be seen as one method of asserting power in interactions with others (Dennis \& Martin, 2005; Jenkins, 2008).

\section{Methods}

This work analyzes data collected as part of a larger, longitudinal study of families dealing with chronic illness. To achieve variety in experiences with chronic health conditions, the study enlisted type II diabetics and persons with HIV/ AIDS (PHAs) and their families. We recruited patients from health clinics, disease-specific community agencies, and a university research participant database in a midwestern state. We screened patients based on their willingness and ability to both discuss their family relationships and recruit members of their family to also participate in the study. We allowed patients to define their families, recognizing the diversity of American family structures (Coleman \& Ganong, 2004). This resulted in diverse groups, including biological families, step-families, and "chosen families" (Weston, 1991), which includes friends that participants defined as family because of the closeness of their relationships.

The full study included five interview visits with each family: interview one is an individual interview with each study participant (patients and family members separately), the three middle interviews are family group interviews (the same patient, with members of their family), and interview five is another individual interview with each study participant. This paper reports results from the first interview with each patient and the first family group interview with the same patient and members of his or her family. Thus, we analyzed transcripts of 30 semi-structured, individual patient interviews (15 diabetics and 15 PHAs) and 30 semistructured, family group interviews with these same patients and their family members. A team of five interviewers, including the two authors, conducted the interviews over the course of approximately 18 months between January 2011 and June 2012. The same semi-structured interview protocol, designed based on the larger study's research questions, was used in each interview visit. We used follow-up questions (Rubin \& Rubin, 2005) as needed to probe or clarify participant responses. Interviews were audio-recorded and transcribed verbatim to facilitate analysis.
As mentioned earlier, we draw on the SI paradigm in micro-sociology and thus adopt the "interaction" as our key unit of analysis (Charon, 2010). We analyzed interactions between people, between people and information, and within the self. We drew on participant accounts in individual interviews, as well as direct observation of interactions in the context of family group interviews. Open coding (Strauss \& Corbin, 1998) of interview transcript data was accomplished using NVivo qualitative data analysis software. An initial codebook was developed based on theoretical concepts in the literature and our research question. After we coded 15 patient interviews, we reviewed the coded data blocks and wrote analytical memos (Strauss \& Corbin, 1998) to explore the categories. After this process, we expanded the codebook by adding emergent, inductively derived categories. We then re-coded the initial 15 patient interviews, as well as the remaining 45 interviews. We routinely wrote analytical memos after coding five interviews, which allowed us to stay close to the data while conducting the constant comparative method (Glaser \& Strauss, 1967).

We used a grounded theory analytical method following Charmaz's constructivist approach, which recognizes that, as researchers, "[o]ur imaginative renderings of what we see and learn are interpretations, emanating from our dialectics of thought and experience" (Charmaz, 2006, pp. 146-8). Given grounded theory's methodological roots in symbolic interactionist sociology (Herman-Kinney \& Verschaeve, 2003) this approach was particularly valuable for our goal of analyzing information use in interaction and accounts of interaction. The aforementioned theoretical frameworks inform our findings and analyses.

\section{Results}

\section{Participant Demographics}

In total, 72 individuals were interviewed, including 30 patients and 42 of their family members and/or friends. The individual patient interviews ranged in length from 50 to 125 minutes, with a mean of 89 minutes and a median of 90 minutes. The family group interviews ranged in length from 30 to 150 minutes, with a mean of 90 minutes and a median of 85 minutes. Of the patients, half were diabetics $(n=15)$ and half were PHAs $(n=15)$ with a mean time since diagnosis of 153 months (13 years) and median time of 139 months (12 years) (Table 1$)$. Of the 42 family member and/or friend participants, 27 were family by blood or marriage and 15 were friends (Table 2). Of all participants, 38 $(53 \%)$ were female, 42 (59\%) were White/Caucasian, 52 (72\%) had some type of education beyond high school, and $43(60 \%)$ were unemployed, retired, or disabled. Demographic details are reported in Table 2.

\section{Everyday Biomedical Information Use}

Patients talked about several ways they use biomedical information in everyday life interactions with themselves 
TABLE 1. Characteristics of sample-patients

\begin{tabular}{lc}
\hline Characteristic & \\
\hline Diagnosis & \\
$\quad$ Diabetes & 15 \\
HIV/AIDS & 15 \\
Total & 30 \\
Time since diagnosis (in months) & 152.83 \\
Mean & 139 \\
Median & \\
\hline
\end{tabular}

TABLE 2. Characteristics of sample—patients and family members or friends

\begin{tabular}{|c|c|c|}
\hline Characteristic & $n$ & $\%$ \\
\hline \multicolumn{3}{|l|}{ Participant Category } \\
\hline Patient & 30 & 41.6 \\
\hline Family member of patient & 27 & 37.5 \\
\hline Friend of patient & 15 & 20.8 \\
\hline Total & 72 & \\
\hline \multicolumn{3}{|l|}{ Sex } \\
\hline Male & 34 & 47.2 \\
\hline Female & 38 & 52.7 \\
\hline \multicolumn{3}{|l|}{ Age } \\
\hline $18-29$ & 3 & 4.2 \\
\hline $30-39$ & 3 & 4.2 \\
\hline $40-49$ & 17 & 23.6 \\
\hline $50-64$ & 39 & 54.1 \\
\hline 65 or older & 10 & 13.8 \\
\hline \multicolumn{3}{|l|}{ Race } \\
\hline Black/African American & 27 & 37.5 \\
\hline White/Caucasian & 42 & 58.3 \\
\hline Native American & 2 & 2.7 \\
\hline Asian & 0 & 0 \\
\hline Hawaiian/Pacific Islander & 0 & 0 \\
\hline Other & 1 & 1.4 \\
\hline \multicolumn{3}{|l|}{ Ethnicity } \\
\hline Hispanic & 3 & 4.2 \\
\hline Arabic & 0 & 0 \\
\hline \multicolumn{3}{|l|}{ Highest level of education } \\
\hline Grade 8 or less & 3 & 4.2 \\
\hline Grades 9-12, no diploma & 4 & 5.5 \\
\hline High school graduate or equivalent & 13 & 18 \\
\hline Some college & 18 & 25 \\
\hline Associate's degree & 9 & 12.5 \\
\hline Bachelor's degree & 16 & 22.2 \\
\hline Graduate degree & 8 & 11.1 \\
\hline Professional degree & 1 & 1.4 \\
\hline \multicolumn{3}{|l|}{ Current employment activity } \\
\hline Full-time work & 17 & 23.6 \\
\hline Part-time work & 9 & 12.5 \\
\hline Full-time student & 3 & 4.2 \\
\hline Part-time student & 0 & 0 \\
\hline Unemployed & 22 & 30.5 \\
\hline Other & 21 & 29.1 \\
\hline
\end{tabular}

and with their family members. Four main interactional forms of biomedical information use emerged from analyses. Interactions with the self mobilized information in the process of understanding my body, whereas interactions with other people employed information in interactions that we identify as mapping the social terrain, asserting autonomy, and puffing myself up. Through these interactions, patients use biomedical information as a resource to gain mastery over their condition, position themselves socially vis-à-vis others, assert dominion over the terms of their condition, and claim authority.

\section{Knowing My Body}

Knowing my body involved the many instances in which patients interacted simultaneously with biomedical information and the self to understand their bodily experience. Through individual accounts, patients spoke of interactions that involved combining an awareness of their embodied experience with information from test results, to develop a knowledge which folds meanings regarding the biomedical aspects of the condition together with patients' own, individual experience of the condition as rendered significant through a process of self-indication.

Patients constructed this knowledge most often in the process of discerning the patterns of their condition. Here, patients used both previous and emergent bodily experiences interactively with test results in the process of indication with the self: have I experienced this before? How is it different? What could be causing this? What's caused it in the past? How do I change it? By interpreting both past and present experience in the process of planning future responses or actions, patients transform self-indications regarding bodily sensations and biomedical information into a knowledge of their condition. This knowledge, following Mead and Morris (1940), allows patients to foster hypotheses regarding actions. In turn, this facilitates a sense of psychological mastery over a problematic situation. As one diabetic patient stated:

I had been going through the ups and downs and I wanted to maybe see them on a chart. So I asked ... "can I look at this, can I get all my readings?" . . . and he gave me the chart . . . and then I came back and made my spreadsheet and . . . I can match it up to the stressful periods of my life.

By comparing prior results, she was able to make connections between aspects of her psychological state that she had pointed out to herself, and its effect on her condition. Making this connection was part of constructing a deeper understanding of how to respond to her condition in future problematic situations: "That's how I kind of realized that it was stress that was causing [my HbAlc to go up] ... and [now] I know, when I'm stressed, my sugar is going to be off." Another diabetic patient inferred that there was an impact of evening meal choices on the next morning's glucose readings: ". . . recently ... in the last few months, I'm getting better about figuring out how to get lower readings in the morning . . . if I have rice instead of potatoes at night, you know, that's a lower blood sugar in the morning."

By braiding indications about their lived bodily experience together with biomedical information, these patients 
are able to create knowledge that allows them to respond to their condition. The body becomes an interactive site to hypothesize, test - and in turn, comprehend - the condition: What patterns emerge if I compare labs with other aspects of my life, like work? Is what I'm experiencing now different than what I've experienced before? The iterative process of indication-response blends embodied experience with biomedical information, allowing these patients to cultivate a knowledge that included a felt understanding of both their bodies and the biomedical information they use. This knowledge is close, personal, and real; it is intimate and meaningful for patients, enabling action to address disease-related problematics, such as a high blood sugar reading, in the context of their everyday lives. Rather than a removed, abstracted biomedical information, this is a kind of information made tangible and intelligible through an interactive process of embodied knowledge construction.

\section{Mapping the Social Terrain}

Patients also used biomedical information in interactions with others to position and locate themselves in social situations with family members and friends. These were instances of mapping the social terrain, which involved discerning how much others understood the patient's conditions, so as to generate a meaning as to one's "place" in relation to others. This finding resonance with the early SI concept of the "looking glass self" (Cooley, 1902), which asserts that we continually observe and assess how others view and judge us and that these observations in turn impact how we see ourselves. In others words, mirroring is the raw material from which our identities are sculpted. We see such processes when patients are engaged in witnessing others and feeling out.

Witnessing others. Through individual accounts, some patients described a painful awareness that very few understand their experience of illness. These experiences involved those interactions where patients described witnessing others' comments and actions. Through the process of witnessing others, patients gauge how much (or how little) their friends and family members understand, or have internalized biomedical information and attitudes regarding the disease. The behavior of others also tells patients about whether others have assigned stigmatizing meanings, and developed associated attitudes regarding their condition. For some PHAs, others' lack of understanding resulted in social network shedding: chatty co-workers suddenly became standoffish, old high school friends no longer called. For other PHAs, witnessing others' actions meant not a shedding of their social networks, but rather a brittling of ties through misunderstandings. Over and over, PHAs talked about their friends' and family members' basic misunderstanding of how HIV/AIDS is transmitted. For some, this involved stories in which PHAs were caricatured by others as carriers. As one PHA painfully shared:
Well I think the biggest shock I got out of all of this was my brother when he found out, he told me not to sit in his truck He said that ... "I could catch it from you sitting on my truck seat." Well . . . it just crushed me that my own family would say that.

Assuaging others' fear of contagion is a menacing chore: annoying and unreciprocated. One PHA recounted how she caught toxoplasmosis when she was helping her brother clean his house. Her brother didn't understand that exposure to the parasite caused the infection, not HIV/AIDS itself. "People don't realize, they think we're gonna hurt them, but see, you can hurt me." Another PHA talked about how his sister was surprised when he explained how worried he was about the common cold:

... we had a conversation [about] ... my health. I gave her a little bit of insight on how I worry [that a cold] will send it into, uh, areas that you don't, that you don't want to go to ... she said, "Well, that's pretty much normal with everyone, nobody likes a cold," and I says, "Yes, but with HIV, it can easily slip into something much more dangerous. You know, a simple cold can turn into pneumonia." And she says, "Really?" She was surprised.

Pervasive, witnessing others' ignorance can be alienating, even in crowded rooms. Will there be a scene? Should I even go? Family gatherings become minefields. One PHA recalled a family event where his grandmother refused to accept a glass of water he prepared. Betrayal seeped through his account: “'Really? Did you go there? I can't tell you nothing no more' . . I don't, I don't think I can talk to her no more about, you know, about anything about me." Another PHA talked about how her aunt wouldn't let her help clean up after family meals:

I would notice, like we'd have dinners over at her house . . . and I would always be the one that used to wash the dishes before we leave her house and all that, but then I noticed that now she makes a scene and is like, "No, no, I'll get it, I'll do this, I'll make sure, I'll clean," and everybody, even my mom noticed it too but we never really said anything because we knew what she was dealing with and I knew she probably just felt uncomfortable because she wasn't sure . . . but it left me wondering like, "Well what did she do when I left, you know, what did she wipe down when I left?"

These testimonies illustrate that some patients witness and wrestle with others' ignorance of biomedical information regarding their condition through direct, in-your-face interactions. These interactions, with all of their painful associations, can become an isolating force in the lives of patients; they can become an unrelenting reminder that others have adopted stigmatizing attitudes towards them.

Diabetics, too, must routinely witness others' misunderstandings or failures to grasp biomedical information regarding their condition. This ignorance manifests itself most often through the interrogation of patients' food 
choices. Judgmental words, looks, and actions can erupt around certain selections. Unlike PHAs, who were seen as dangerous, people with diabetes were treated as morally culpable, and in need of regulation by others. For some, meals become battles, for others, every snack is a skirmish. Food, for some, now means a dreaded interaction rather than a satiating experience. Sugar becomes a loaded word: a bitter symbol of others' inaccurate, over-simplified understanding of the patient's condition. "People are slightly familiar with [diabetes], they know what it's kind of about," one diabetic patient shared, ". . . so you know, I'll find that people say, 'Oh you can't have that cookie,' or 'You can't have this.' Well I can have a cookie, I can't have a whole bag of cookies, that's the difference."

Frustration over the contentiousness surrounding sugar was a very common topic in the interviews with diabetic patients. Indeed, misunderstanding around sugar was so routinized for some, they talked of predictable interactions concerning it. "If you went in a room of 50 people and say, 'How many of you think that it's not healthy for a diabetic to eat sugar?" " one diabetic patient stated, "I'll bet you almost every hand will go up in there, except for the diabetics." Another diabetic talked about this indictment of sugar:

Sometimes when people try to police what I'm doing . . . as far as like they might've seen me eat something sweet, but okay my sugar level's down right now, I have to bring it up and they don't understand a doctor will tell you, "Keep peppermint on you," and they'll always "Well you're not supposed to be eating that, that's candy!" You're supposed to carry candy on you [in case] your sugar level drops low ... [I] end up having to tell them, yeah, it's like "Well, you get off my back!"

Another diabetic used vivid language to capture how these situations make her feel attacked:

this is why I don't tell a lot of people that I am even dealing with diabetes, "Oh, you're not supposed to be eating that," ... they think it's like a crime, I'm like "Don't crucify me because I'm eating a little bit of sugar" ... and it's like you cannot be comfortable like that.

In these interactions, patients use others' comments as a way of deciphering how much others' understand the condition.

Although some diabetics dread these interactions, others feel conflicted about condition-related interactions with their close friends or family members. Patients do not want to be berated, but they also do not want to be forgotten. Some diabetics craved these diabetes-related comments and actions as a welcome sign that their family members even think about them. For them, these interactions were seen as a symbol of others' care for them. This was especially salient in stories of the isolation that diabetics frequently experience at social gatherings. When appropriate food options are not offered, diabetics often feel left out. Do they even think about me when planning? Do they care that limited options mean I can't join in on the fun? These stories coalesce frustration and annoyance with hurt and feelings of neglect. "Okay, well you didn't think about the fact that ... millions and millions of people have diabetes? Wow! I mean it's just ... [an] absolute lack of awareness." But feeling forgotten goes beyond just a desire to be included at parties: patients worry that oversight, disregard, silence means their experience-the experience of grappling daily with chronic illness and its impact on one's mortality - is forgotten, ignored, obliterated. One diabetic talked about how he feels his kids aren't concerned, his voice tentative and slow as he poignantly stated: "They don't particularly care about [my diabetes]. Because ... they, they don't know ... they don't understand it ... it [can] destroy my organs, you know."

These accounts shed light on how some patients use biomedical information in the interactive process of appraising how much others' understand-and care about - their condition, and by extension, how others appraise them in the context of their illness. Patients did this by witnessing their comments and actions.

Feeling out. Another way that some patients use information in interactions with others to appraise how much others understand their condition is by feeling out others. These involved instances in which patients quizzed friends and family members to ascertain how much biomedical information they had retained regarding the patient's condition. Patients then decided how much biomedical information to share with them. As one PHA recalled: "I wanted to feel her out and find out, you know, what she knew about HIV/ AIDS." He went on to say, "she doesn't really know a whole lot." But he went on to add: "I'm looking at it that, you know, I'm going to be able to educate her." These instances of quizzing were usually grounded in a desire to help family and friends understand the illness, rather than challenging or confronting their ignorance. As one diabetic patient explained: "I ask ... questions and it lets me know where they're at, then it lets me know how much [information] I can give them to help them understand where I'm at." More active than instances of witnessing others, the process of feeling out involved patients using biomedical information that they had internalized to actively survey the landscape of their friends and family members' conditionrelated understanding and attitudes, so as to later intervene in others' appraisals of their identities as chronically ill people.

By witnessing others and feeling out, patients use biomedical information to situate themselves vis-à-vis others, and understand how they are seen, and evaluated, as people with HIV/AIDS or diabetes. This situating tells patients how close or far others are from them in terms of biomedical comprehension, which, for some, serves as a symbol of affiliation and care. Thus patients use this process of social location to determine and interpret the extent to which others empathize with and/or care about them as people dealing with a chronic illness. 


\section{Asserting Autonomy}

Asserting autonomy involved those interactions in which patients used biomedical information in a process of affirming independence and control over the terms of how they managed their condition. These instances involved testing the limits of orders and resisting relevancy. When testing the limits of orders, patients interacted with biomedical information and the self in deciding when and how far they could challenge doctors' directives. When resisting relevancy, patients used biomedical information to question the relevance of health-related information that family members or friends gave them during interactions; patients accomplished this by processes of individualizing or "nothing new"-izing.

\section{Testing the Limits of Orders}

Testing the limits of orders involved instances in which patients interacted with both biomedical information and the self, asserting autonomy in actions that expressed resistance towards their health care providers. This involved deciding how and when to adjust treatment and finding ways to work around drug side effects. Notably, this was often pursued independent of medical supervision, and at times went against health care provider advice. Self, as mentioned, is a social object, both an actor and an object (Charon, 2010; Weigert \& Gecas, 2003). Symbolic interactionists have explored how the self is constrained by institutions through the imposition of roles, or expected behavior, especially in the context of medical institutions, resulting in a loss of autonomy (Charmaz, 1991; Charmaz \& Olesen, 2003). Interactionist Goffman (1961) observed that patients carve out spaces of resistance to the expected role of "good" patient, in an effort to maintain at least a token of control over one's self (autonomy) vis-à-vis the clinician's control over one's self. We observed a similar phenomenon with the patients in our study. Using biomedical information (i.e., their lab test results) as an indicator of success or failure, patients make small changes to their medication regimens in an attempt to gain autonomy over the management of their condition or improve the quality of their lives.

For example, one diabetic participant talked about his decision to increase his insulin dosage to help stabilize his HbA1c. "I was reading 12 A1c ... they said I was way out of control, but my doctor he would raise the insulin only 5 or 6 units . . . You know, use a little bit of common sense, that's not going to do anything." He used his HbA1c reading as an indicator of whether he was taking enough insulin to effectively manage his diabetes: "Well, I'm going to add more than 5 or 6 units to get my blood sugar down . . . [so now] I take [25 more units] in the morning . . . and that brought [my HbA1c] quite a bit down." Another diabetic participant talked about independently adjusting her medication dosage without direct medical supervision. She relied on her daily glucose readings in deciding whether to skip: “. . . the doctor had said, 'Take a [particular pill] in the morning with you know, before breakfast' and ... I was having low blood sugars all the time and ... I stopped with the [particular pill] in the morning and that ... resolved that issue."

Another diabetic patient also talked about deciding to take a supplemental anti-diabetic drug from her regimen. She used her blood glucose readings as an indicator she didn't need the additional pill: "it started going down on its own, you know, so then I figured, well if it's going down, why go to another pill?"

PHAs also talked about developing ways to work around doctors' orders, particularly to ameliorate drug side effects. Instead of adjusting dosages, one PHA's strategy involved the timing of a particular medication to help alleviate vertigo, a debilitating side effect of the medication. Through a process of experimentation, he determined that if he took the medication right before he went to bed for the night, he could sleep through the roughest parts of the vertigo. This PHA went on further to elaborate on the interaction between self, roles, and biomedical information. He expressed his desire to comply with his medication regimen (i.e., perform the role of "good" patient) but that it conflicted with the demands of a different social role (i.e., student):

When I'm studying, I may study until 3:00 or 4:00 or 5:00 in the morning ... So then I have to make a decision, do I take my medicine at 5:00 in the morning and then have that spinning head when I wake up at . . 8:00, and so . . . if I'm up to 4:00, often I won't take it . . . but I try not to miss it more than once in a week.

He reflected on a recent increase in his viral load, which came after final exams: "[The recent increase] made me realize that I can't skip my medication . . . I mean two days it jumped up [15 points] . . . before that happened I thought, 'Oh, it'll take a week or more for it to go up.' " This illustrates an interactional process of biomedical information use. Like the diabetic patients' stories of testing the limits of orders, this PHA used his lab test results as a barometer to gauge just how far he could stretch his doctor's order. These patients test doctors' orders. By making micro-edits to their medication regimens, they claim agency over the everyday details of how to manage their condition and work to maintain control of the self in the process. Biomedical information (i.e., their lab results) becomes a safeguard, helping them traverse the line between too much and not enough, while maintaining some autonomy over when and how they perform the social role of "patient."

Resisting relevance. Using biomedical information in asserting autonomy also involved a process of resisting relevance. During interactions with others, patients assessed the relevancy of health-related information given to them by friends or family members. Patients decided what was relevant to them and thus, what information they would reject as irrelevant. Patients resisted relevance by individualizing and "nothing new"-izing. 
Individualizing. Individualizing arose when patients rejected health-related information from family members or friends by declaring it was not relevant to their situation, emphasizing their experience of the condition as unique and specific. Not all information on this topic is relevant to my experience. Do they think every patient is the same? Don't they know I'm different? Here, patients use biomedical information in a struggle to maintain personal identity (as an individual) over others' attempt to enact their social identity (as a diabetic or PHA). For example, one diabetic patient talked at length about her sister, who would give her anything she saw that mentioned diabetes. The patient described this, with frustration: "[my sister] thinks just because it's about diabetes ... it might be about neuropathy, which doesn't affect me ... it's like yeah, this is an article about diabetes, but I don't have this problem."

Even if patients felt the information wasn't relevant to them, some would passively accept it and disregard it after the encounter: "It's like I don't care about all this stuff that she throws out there, you know, I mean I can get . . . my own information ... sometimes I just don't say anything. I just say, 'Oh thanks, I'll read that when I get home.' . . . but I don't." Another diabetic patient placated his wife, when she mentioned something she heard on the news about diabetes: "I told her I was going to look it up and I didn't . . I I don't think it was something that really pertained to me."

For some patients, individualizing also occurred in interactions with information produced by family members and close friends with similar social identities (i.e., other patients with their condition). One diabetic patient resisted attempts by his father, who is also a diabetic, to compare experiences or information: "the specifics for me are different than for him." One PHA also talked about how it wasn't necessarily helpful to swap notes with a friend of his, also a PHA. "[You can] get all perspectives on whatever the topic might be ... but everybody that has HIV deals with it in different ways ..."

In these instances, patients resisted attempts by others to impose social identities-and in turn, information relevancy - on them. Instead, patients used their own personal knowledge of their condition and their expertise gained through interaction with biomedical information and their bodies, to determine what health-related information was relevant to them and what health-related information was not, thus enacting their personal identity as an individual rather than their social identity as a patient in the interaction.

"Nothing new"-izing. Another way that some patients resisted relevancy was by "nothing new" -izing. These were interactions that patients had with others in which the patient received health-related information from family or friends and, in turn, deemed it as "old" information-information that the patient was already familiar with and, as many patients described, was "nothing new." As one patient noted, "A lot of the stuff . . . I've already researched or found out on the computer." Patients used the biomedical information they were already familiar with how to re-define the terms of the interaction. Rather than one defined by the family member or friend's terms, the patients defined the interaction on their own terms. "He might just say, 'Did you hear such and such?' and I'm like, 'Oh yeah, I already know about that,' and then I'll go on about my business."

For some, these interactions were viewed as valuable because they were seen as a symbol of care, signifying that friends or family members were thinking of them. In SI, as mentioned earlier, a symbol is an object or gesture with a shared meaning (Hewitt, 2003). As noted by one PHA, the HIV/AIDS-related information his father sometimes gave him was once such symbol of care: "[They are] things I already know . . . but it makes me feel good that somebody else is thinking, too . . . and has my interest at heart." These interactions showed that even when patients resist the relevance of the information by deeming it old or "nothing new," it may still hold some value to them as an interactional symbol that others care for them.

These stories of resisting relevance highlight the contextual, conflicted nature of relevancy. Relevancy, in these interactions, is contentious. On the one hand, biomedical information is relevant in that patients use it as a resource to define the terms of the interaction. They assert their personal identity by claiming their individuality and the uniqueness of their experience. I am not simply "patient," I am me. On the other hand, even when biomedical information is relevant not in and of itself, per se, it may be valued as a token symbolizing others' concern or care for them. In this way, patients interact with both biomedical information and others in the emergent process of resisting relevance, yet still using others' attempts to share information as an indicator of how others perceive and evaluate the self.

\section{Puffing Myself Up}

Puffing myself up included those instances in which patients interacted with others, sharing health-related information and appropriating cognitive authority in the process. As we have seen, through their experience of illness, some patients use biomedical information in asserting autonomy. In those instances of asserting autonomy, patients claim that I know what's important. For some, these claims go a step further: I know what's important puffs up to I know what's important and you should listen. These patients do not passively, but actively attempt to influence others. These stories of puffing myself up involved evoking institutional authority and warning others.

Evoking institutional authority. Some diabetic patients talked about sharing biomedical information with others, typically nutritional information, while evoking the institutional authority of healthcare professionals. These stories involved sharing information with other diabetics and also non-diabetics. One diabetic participant recalls an incident with her diabetic friend: "she had some cookies and I'm like, 
'You eating cookies? Didn't they tell you?' " Using the proverbial "they," she elicits the symbolic authority of biomedical institutions to bolster the potential influence of the information she shared with her friend. In these interactions, patients use the institutional authority of healthcare professionals to elevate and protect the authority of the information they are sharing in an attempt to influence others. Using biomedical information in this way, the institution serves as a symbol of power (Dennis \& Martin, 2005) that legitimates the patient's claim of authority and attempt to influence others.

Warning others. Puffing myself up also included those instances of warning others. In these interactions with others, patients used their own experience as the basis of their authority. Rather than evoking the symbolic power of the medical institution, patients in these interactions perform a different kind of locally authoritative role. This performance involves presenting a socially valued or idealized self as role model (Goffman, 1959). Here, this valued self is the role of patient as the cautionary tale: watch out or you'll end up like me! For diabetic patients, warning usually involved telling non-diabetic family members about the potential consequences of their food choices. As one diabetic patient recalled: "I reminded [my sister] yesterday, I said, 'You keep on like this, you're going to be on the same medicine I'm on." "Another diabetic talked about the food choices her brother makes: "Well I did, I got upset with him because of the way he eats ... the way he eats bothers me ... I told him yesterday I said, 'You know, it just makes me sick to see you do this.'"

This idealized performance was also seen in some family group interviews. In these instances, the patient and family member(s) would work together to maintain the impression of the patient-as-valued-self, both in the emergent interaction of the interview and in describing interactions with family members.

[Family member:] ... When we're around [our brother] we're trying to demonstrate and verbally say to him you know this is what is helpful for [patient's name] to watch food.

[Patient:] He'll come back and say 'I'm only pre-diabetic' and I said but if you keep feeding your face the way you are ... you're gonna become diabetic ...

In this example, we see the family member describe a past interaction in which she and the patient worked together to maintain the patient's role as experienced authority, in this case, exemplified by his right to warn their brother. Through the emergent interview process, we see the patient and family member work together interactionally to present and perpetuate the patient's role-of-valued self.

Some PHAs also talked about warning others. In these interactions, patients dealt with friends or family members whom they saw as engaging in "risky" behavior; consequently, PHAs attempted to caution them regarding the potential consequences. One PHA talked about his close friend, who occasionally engaged in unsafe sex practices: every time he has a slip up...he describes the act, I'm like, "Lord have mercy, why didn't you [use a condom]?" ... [my family and friends] know I'm ... going to preach to them because they ... screwed up and [weren't safe] . . I'm going to be a little bit perturbed ... that they don't have a clear sense of a possible harm.

In these interactions with others, patients use biomedical information in the process of performing a certain kind of role-one of authority - whether appropriated from biomedicine or based in personal experience. Although the concern for the health of family members and friends is no doubt genuine, these performances can be seen as attempts by patients to create the image of themselves that they want others to have of them: the image of the socially valued, idealized patient (Goffman, 1959), who is an authority about matters related to their condition. In these interactions, patients use biomedical information as a symbol to maintain and amplify their performance of the socially valued, idealized—and authoritative - patient.

\section{Discussion}

This work shows that the way these patients use biomedical information in their everyday lives is much more dynamic and social than individually focused research would suggest. Through interview accounts and direct observations, we gain a glimpse of the many ways in which patients use biomedical information in their everyday interactions with other people and with the self. These results followed four interactional themes of biomedical information use: knowing my body, mapping the social terrain, asserting autonomy, and puffing myself up. These themes highlight interactions wherein patients use biomedical information as a resource to address problematic situations with their conditions, locate and understand their social position, claim control over the terms of their condition management, and attempt to influence those around them.

Our work theoretically extends information behavior research by applying the micro-sociological paradigm of SI. SI allows us to focus on the ways information is used in accounts of a wide variety of everyday life interactions within the self, and between family members. In doing so, we answer the call for expanded attention to the social dimensions of information behavior (Hjørland, 2002; Pettigrew, Fidel, \& Bruce, 2001) particularly in everyday life contexts (Savolainen, 2008; Talja, Tuominen, \& Savolainen, 2005). Helpfully, an SI perspective also allows us to conceptualize information use as an emergent process in which the self and others are simultaneously and iteratively constituted. As such, this perspective also provides resources for connecting information use to broader sociological concerns; these include the body, emotions, and social order (e.g., Reynolds \& Herman-Kinney, 2003). The ability to make such connections facilitates a more comprehensive understanding of information's place in society. 
Our theoretical contribution also includes an expansion of our collective conceptualization of information use in assertions of everyday authority. We extend Tuominen and Savolainen's (1997) exploration of an important social form of information use: its use in the assertion of everyday authority claims. We build on this by showing that contests regarding credibility are not the only ones that emerge in information use: rather, assertions of "relevance" may also be contested. We also offer the novel insight that biomedical information may be used to assert individual autonomy in the face of felt biomedical encroachment upon patients' everyday lives. In this sense, our findings follow de Certeau's (1984) theoretical stance that everyday life is a site of appropriation-a process whereby dominant cultural resources are re-defined and mobilized for local purposes.

The present research also generates new theoretical insights by highlighting information use in the construction of self and identity. Although recent information behavior investigations show that identity may play a role in information acquisition and literacy (e.g., Rivano-Eckerdal, 2011a), and in the construction of health care as a matter of "choice" (Mol, 2008), the relationship between information use and identity has received little attention in the literature. Our focus on information use in the construction of self and identity draws on a key sociological concern: the relationship between modern institutions and the self (Gubrium \& Holstein, 2001). As mentioned, the self is understood by SI to be a product of active construction: interactively with others, and reflexively with the self (Callero, 2003). All people, whether ill or not, may draw upon various symbols as resources in the construction of "individual selfmeanings," or identities (Callero, 2003). SI researchers have previously identified the profound effects of chronic illness on the self: biographical disruption, personal loss, reduced autonomy, and psychological suffering (Charmaz \& Belgrave, 2013). Further, Goffman (1963) highlights the stigma that can emerge from physical difference and disability. Consequently, it is argued, patients and their caregivers may engage in "identity work" to help ill people "maintain and improve a sense of identity in the face of ... illness" (Strauss, Fagerhaugh, Suczek, \& Wiener, 1997, p. 156). Although previous sociological research has highlighted the use of resources such as stories, cultural narratives, and political ideologies to construct identity (Callero, 2003), our findings are unique in demonstrating the symbolic use of biomedical information to construct a valued self, one who has authority and should be listened to. This is a critical insight because identities can be powerful determinants of social action (Callero, 2003).

Attention to identity construction also leads us to a greater empirical appreciation of the role of a wider range of emotions in information behavior. Previous research has shown that information behavior may be motivated by emotions, and that specific emotions such as fear/anxiety may be a result of information seeking and use (Kuhlthau, 2004; Lee et al., 2008; Nahl, 2007; Veinot, 2010). We extend this by noting relationships between information use and more "social" emotions, such as shame and caring (Scheff, 2003). Specifically, the use of biomedical information to create and maintain a valued "self" implicates the SI insight that the avoidance of painful emotions such as embarrassment and shame are key motivators in human interaction (Goffman, 1959; Scheff, 2003). This may be all the more important in the context of illness-related stigmatization and judgment experienced by many of our participants. Furthermore, biomedical information sharing was seen to express interpersonal care, thus eliciting positive emotions and potentially strengthening emotional attachments between family members. Such a potential contribution of health information sharing to relationship building has been identified in clinical contexts (Salander, 2002), but has received less attention in everyday life-focused research (e.g., Veinot, Kim, \& Meadowbrooke, 2011). Broadly, this work suggests a need for greater attention to the social emotions that may inform interactions, including, potentially, those with information professionals such as librarians.

The present research also contributes theoretically to a growing dialogue regarding the relationship between information and embodiment in information studies. For example, McKenzie (2003) explored patients' tactics when biomedical information contradicted personal, embodied experience, finding that patients often discredited their embodied experience in favor of clinical information regarding pregnancy with twins. The rarity of the condition led some patients to feel isolated and unsure of their own experience, thus giving credence to specialized, clinical information. Veinot (2010) and Hartzler and Pratt (2011) also highlighted the difference and complementarity between biomedical information and patients' experiential information, the latter of which focuses on embodied practical strategies and psychosocial concerns. The work of Somerville and Lloyd (2006) and Lloyd (2010) has also highlighted the difference between information and bodily experience (there, in the context of safety awareness in hazardous occupations). By contrast, our findings emphasize the interplay between "indications" regarding one's bodily experiences and biomedical information (in our case, biomedical information in the form of viral load in HIV/AIDS and HbA1C in diabetes) in the construction of knowledge about bodies with these conditions. In this sense, the body is neither discounted nor kept separate: it is a site of information use. Although Rivano-Eckerdal (2012) has explored ways in which clinicians use information to construct the patient body during the clinical interview, our work highlights embodied information use by the patient in everyday life. Thus we offer a new way of conceptualizing information use as an embodied process of knowledge construction involving one's own body, not the bodies of others. This perspective may offer fruitful new research directions for information behavior researchers.

Our findings also extend prior research on the knowledge-behavior nexus. Rather than simply mapping the relationships between health knowledge and behavior change as in the health behavior literature (Rimal, 2000; 
Sheeran, 2002; Sligo \& Jameson, 2000), we found that health behavior change efforts did not transparently flow from the directives of health professionals. Patients correlated their personal experience with biomedical information while constructing knowledge of their bodies, and used biomedical information to assess their efforts to challenge such directives. Furthermore, behavior change may not be the sole or even primary way in which biomedical information is used in everyday life. Indeed, achieving felt belonging and constructing a valued self were among the uses we observed. Such social uses of health information suggest a role for information technologies and services in remedying the personal losses that may emerge from chronic illness (Charmaz $\&$ Belgrave, 2013). Accordingly, our findings complicate the dominant idea that patient use of biomedical information is equivalent to following instructions.

Our work also expands on communication studies literature that has addressed health and biomedical information use by showing that the process is not "one-way"; rather, information use is a dynamic, emergent process of interactions between people and institutions, as our categories illustrate. It is through these processes that both people and institutions are constituted and given meaning-they interact; institutions do not merely act on people. Our findings broaden the literature's conceptualization of institutions on top and people on bottom. Understanding that the relationship between the two is interactional and dynamic (not unidirectional and static) helps us to more fully understand the ways in which information may be mediated-and transformed-in everyday life. Moreover, the categories of information use presented here provide health information professionals with fresh resources in their ongoing efforts to articulate the impact of information services (e.g., Durrance, Fisher, \& Hinton, 2005).

We also note that there are significant parallels between our inductive findings and extant social psychological theory. Self-determination theory (SDT) hypothesizes that three experiences (autonomy, competence, and relatedness) are necessary to achieve psychological well-being (Deci \& Vansteenkiste, 2004; Ryan \& Deci, 2000). When unmet, these psychological needs motivate people to seek out experiences to fulfill those needs (Sheldon \& Gunz, 2009), though actions to fulfill these needs are not necessarily conscious (Ryan \& Deci, 2000). Social experiences are important in meeting these goals. For example, social settings or environments (Ryan, 1995) and social group membership (Sheldon \& Bettencourt, 2002) can support or thwart needs satisfaction. If these three needs motivate human action, we can hypothesize a potential link between the social uses of information described here and psychological well-being. Future research could valuably explore such a potential relationship in depth.

Several limitations of this research should be kept in mind. The generalizability of our work is unclear. Although our sample size was large for a qualitative study, it was purposively selected. Moreover, our work focuses on interactions in close relationships and with the self, rather than loose forms of affiliation such as acquaintanceship. Our findings regarding identity, belonging, and emotion may have been particularly facilitated by our attention to intimate bonds. We also recognize the possibility of selection bias, because our recruitment of patients was conducted primarily through organizational and professional referral. Thus, our participants may have been more connected to biomedicine than the chronically ill population in the US, particularly those without adequate health insurance. Our findings are also distinctly situated in the context of everyday biomedical information-social uses of different types of information may (or may not) be similar from the uses we have observed. We entreat future researchers to explore ways in which everyday, interactional information use varies in a range of other contexts.

\section{Conclusion}

We examined how biomedical information is used in the everyday life interactions between patients with chronic illnesses and their families and with themselves, from a symbolic interactionist perspective. We found that patients used biomedical information in ways that allow them to gain mastery, locate themselves in social situations, and assert interpersonal power. Our findings suggest that information use in everyday life interactions is a dynamic and social process that may implicate core aspects of social life, including: self/identity, belonging, and autonomy. Thus we offer an expanded conceptualization of information use: We show that information is an interactional resource that can be mobilized as patients struggle for space, while finding their place.

\section{Acknowledgments}

This research was made possible by funding from the Institute of Museum and Library Services (Grant \# RE-0410-0038-10), which we gratefully acknowledge. All views, findings, and conclusions expressed in this article are ours and do not necessarily represent those of the funder.

Christine T. Wolf completed an earlier version of this article as a Master's Thesis at the University of Michigan's School of Information. We are grateful to Soo Young Rieh for helpful input into an early version of this work and two anonymous reviewers whose thoughtful comments strengthened this work. We are also thankful to our research team for their dedicated work. Finally, we are indebted to our participants, without whom this research would not be possible.

\section{References}

Allum, N., Sturgis, P., Tabourazi, D., Brunton-Smith, I. (2008). Science knowledge and attitudes across cultures: a meta-analysis. Public Understanding of Science, 17(1), 35-54.

Anderson, T.D. (2007). Settings, arenas, and boundary objects: Sociomaterial framings of information practices. Information Research, 12(4), paper colis10. Available at http://InformationR.net/ir/12-4/colis/ colis $10 . h$ tml 
Arksey, H. (1998). RSI and the experts: The construction of medical knowledge. Bristol: UCL Press.

Blumer, H. (1969). Symbolic interactionism: Perspective and method. Englewood Cliffs: Prentice-Hall.

Blumer, H., \& Morrione, T.J. (2004). George Herbert Mead and human conduct. Walnut Creek: AltaMira Press.

Borgman, C.L., \& Furner, J. (2002). Scholarly communication and bibliometrics. Annual Review of Information Science and Technology, 36, 3-72.

Callero, P.L. (2003). The sociology of the self. Annual Review of Sociology, 29, 115-133.

Case, D.O. (2006). Information behavior. Annual Review of Information Science and Technology, 40, 293-356.

Charmaz, K. (1991). Good days, bad days: The self in chronic illness and time. New Brunswick: Rutgers University Press.

Charmaz, K. (2006). Constructing grounded theory: A practice guide through qualitative analysis. Thousand Oaks: Sage Publications.

Charmaz, K., \& Belgrave, L.L. (2013). Modern symbolic interaction theory and health. In W.C. Cockerham (Ed.), Medical sociology on the move (pp. 11-39). Netherlands: Springer.

Charmaz, K., \& Olesen, V. (2003). Medical institutions. In L.T. Reynolds \& N.J. Herman Kinney (Eds.), Handbook of symbolic interactionism (pp. 637-656). Walnut Creek: AltaMira Press.

Charon, J.M. (2010). Symbolic interactionism: An introduction, an interpretation, an integration. Boston: Prentice Hall.

Chatman, E.A. (1999). A theory of life in the round. Journal of the American Society for Information Science, 50(3), 207-217.

Choo, C.W. (1996). The knowing organization: How organizations use information to construct meaning, create knowledge and make decisions. International Journal of Information Management, 16(5), 329-340.

Coleman, M., \& Ganong, L.H. (2004). Handbook of contemporary families: Considering the past, contemplating the future. Thousand Oaks: Sage.

Cooley, C.H. (1902). Human nature and the social order. New York: Scribners.

Cornelius, I. (2002). Theorizing information for information science. Annual Review of Information Science and Technology, 36, 393-425.

Cutrona, C.E., \& Gardner, K.A. (Eds.). (2006). Stress in couples: The process of dyadic coping. New York: Cambridge University Press.

de Certeau, M. (1984). The practice of everyday life. Berkeley: University of California Press.

Deci, E.L., \& Vansteenkiste, M. (2004). Self-determination theory and basic need satisfaction: Understanding human development in positive psychology. Ricerche di Psicologia, 27(1), 23-40.

Dennis, A., \& Martin, P.J. (2005). Symbolic interactionism and the concept of power. British Journal of Sociology, 56(2), 191-213.

Dervin, B. (1998). Sense-making theory and practice: An overview of use interests in knowledge seeking and use. Journal of Knowledge Management, 2(2), 36-46.

Dervin, B., \& Nilan, M.S. (1986). Information needs and uses. Annual Review of Information Science and Technology, 21, 3-33.

Durrance, J.C., Fisher, K.E., \& Hinton, M.B. (2005). How libraries and librarians help: A guide to identifying user-centered outcomes. Chicago: American Library Association.

Elliott, T.R., \& Shewchuk, R.M. (Eds.). (2004). Family adaptation in illness, disease, and disability. Washington: American Psychological Association.

Fisher, K.E., \& Julien, H. (2009). Information behavior. Annual Review of Information Science and Technology, 43, 317-358.

Frost, J.H., \& Massagli, M.P. (2008). Social uses of personal health information within PatientsLikeMe, an online patient community: What can happen when patients have access to one another's data. Journal of Medical Internet Research, 10(3), e15.

Glaser, B., \& Strauss, A. (1967). The discovery of grounded theory: Strategies for qualitative research. Chicago: Aldine Pub. Co.

Goff, T.W. (1980). Marx and Mead: Contributions to a sociology of knowledge. London; Boston: Routledge \& Kegan Paul.

Goffman, E. (1959). The presentation of self in everyday life. Garden City: Doubleday.
Goffman, E. (1961). Asylums. Chicago: Aldine.

Goffman, E. (1963). Stigma: Notes on the management of a spoiled identity. Englewood Cliffs: Prentice Hall.

Greene, J.A., Choudhry, N.K., Kilabuk, E., \& Shrank, W.H. (2011). Online social networking by patents with diabetes: A qualitative evaluation of communication with Facebook. Journal of General Internal Medicine, 26(3), 287-292.

Gregory, J., \& Miller, S. (1998). Science in public: Communication, culture, and credibility. New York: Plenum Trade.

Gubrium, J.F., \& Holstein, J.A. (2001). Institutional selves: Troubled identities in a postmodern world. New York: Oxford University Press.

Hartzler, A., \& Pratt, W. (2011). Managing the personal side of health: How patient expertise differs from the expertise of clinicians. Journal of Medical Internet Research, 13(3), e62.

Herman-Kinney, N.J., \& Verschaeve, J.M. (2003). Methods of symbolic interactionism. In L.T. Reynolds \& N.J. Herman Kinney (Eds.), Handbook of symbolic interactionism (pp. 213-252). Walnut Creek: AltaMira Press.

Hewins, E.T. (1990). Information need and use studies. Annual Review of Information Science and Technology, 25, 145-172.

Hewitt, J.P. (2003). Symbols, objects, and meanings. In L.T. Reynolds \& N.J. Herman Kinney (Eds.), Handbook of symbolic interactionism (pp. 307-325). Walnut Creek: AltaMira Press.

Hjørland, B. (2002). Epistemology and the socio-cognitive perspective in information science. Journal of the American Society for Information Science, 53(4), 257-270.

Huang, X., \& Soergel, D. (2013). Relevance: An improved framework for explicating the notion. Journal of the American Society for Information Science and Technology, 64(1), 18-35.

Jenkins, R. (2008). Goffman: A major theorist of power? Journal of Power, $1(2), 157-168$.

Joffe, H. (2002). Social representations and health psychology. Social Science Information, 41(4), 559-580.

Joffe, H. (2003). Risk: From perception to social representation. British Journal of Social Psychology, 42, 55-73.

Kari, J. (2010). Diversity in the conceptions of information use. Information Research, 15(3), colis709. Available at http://www.informationr.net/ ir/15-3/colis7/colis709.html

Kuhlthau, C.C. (2004). Seeking meaning: A process approach to library and information services (2nd ed.). Westport: Libraries Unlimited.

Lambert, H., \& Rose, H. (1996). Disembodied knowledge? Making sense of medical science. In A. Irwin \& B. Wynne (Eds.), Misunderstanding science? The public reconstruction of science and technology (pp. 65-84). Cambridge: Cambridge University Press.

Lee, S.Y., Hwang, H., Hawkins, R., \& Pingree, S. (2008). Interplay of negative emotion and health self-efficacy on the use of health information and its outcomes. Communication Research, 35(3), 358381.

Lin, N., \& Garvey, W.D. (1972). Information needs and uses. Annual Review of Information Science and Technology, 7, 5-37.

Lloyd, A. (2010). Corporeality and practice theory: Exploring emerging research agendas for information literacy. Information Research, 15(3), colis794. Available at http://InformationR.net/ir/15-3/colis7/colis704 .html

Lloyd, A., Bonner, A., \& Dawson-Rose, C. (2013). The health information practices of people living with chronic health conditions: Implications for health literacy. Journal of Librarianship and Information Science, in press. doi: $10.1177 / 0961000613486825$

McCall, G.J. (2003). Interaction. In L.T. Reynolds \& N.J. Herman-Kinney (Eds.), Handbook of symbolic interactionism (pp. 327-348). Walnut Creek: AltaMira Press.

McCarthy, E.D. (1992). George Herbert Mead and Wissenssoziologie: A re-examination. In W. Stark, E.B. Leonard, H. Strasser, \& K. Westhues (Eds.), In search of community: Essays in memory of Werner Stark (1909-1985) (pp. 97-115). New York: Fordham University Press.

McKenzie, P.J. (2003). Justifying cognitive authority decisions: Discursive strategies of information seekers. The Library Quarterly, 261-288. 
McKenzie, P.J. (2004). Positioning theory and the negotiation of information needs in a clinical midwifery setting. Journal of the American Society for Information Science and Technology, 55(8), 685-694.

McKenzie, P.J. (2010). Informing relationships: Small talk, informing and relationship building in midwife-woman interaction. Information Research, 15(1). paper 423. Available at http://InformationR.net/ir/15-1/ paper423.html

McKinney, J.C. (1955). The Contribution of George H. Mead to the Sociology of Knowledge. Social Forces, 34(2), 144-149.

Mead, G.H. (1938). The philosophy of the act. Chicago: University of Chicago Press. Edited by Charles W. Morris with John M. Brewster, Albert M. Dunham and David Miller.

Mead, G.H., \& Moore, M.H. (1949). Movements of thought in the nineteenth century. Chicago: University of Chicago Press.

Mead, G.H., \& Morris, C.W. (1940). Mind, self \& society from the standpoint of a social behaviorist. Chicago: The University of Chicago press.

Meadowbrooke, C.C., Veinot, T.C., Loveluck, J., Hickok, A., \& Bauermeister, J.A. (2014), Information behavior and HIV testing intentions among young men at risk for HIV/AIDS. Journal of the Association for Information Science and Technology. doi: 10.1002/asi.23001

Mikulak, A. (2011). Mismatches between "scientific" and "non-scientific" ways of knowing and their contributions to public understanding of science. Integrative Psychology and Behavioral Science, 45(2), 201-215.

Mol, A. (2008). The logic of care: Health and the problem of choice. New York: Routledge.

Morgan, S.E. (2009). The intersection of conversation, cognitions, and campaigns: The social representations of organ donation. Communication Theory, 19, 29-48.

Moscovici, S. (2000). Social representations: Explorations in social psychology. Cambridge: Polity Press.

Nahl, D. (2007). The centrality of the affective in information behavior. In D. Nahl \& D. Bilal (Eds.), Information and emotion: The emergent affective paradigm in Information behavior research and theory (pp. 3-37). Medford: Information Today.

Newman, D.M., \& Grauerholz, L. (2002). Sociology of families. Thousand Oaks: Sage Publications.

Paisley, W. (1968). Information needs and uses. Annual Review of Information Science and Technology, 3, 1-30.

Pettigrew, K.E., Fidel, R., \& Bruce, H. (2001). Conceptual frameworks in information behavior. Annual Review of Information Science and Technology, 35, 43-78.

Reynolds, L.T., \& Herman-Kinney, N.J. (2003). Handbook of symbolic interactionism. Walnut Creek: AltaMira Press.

Rimal, R.N. (2000). Closing the knowledge-behavior gap in health promotion: The mediating role of self-efficacy. Health Communication, 12(3), 219-237.

Rivano-Eckerdal, J. (2011a). To jointly negotiate a personal decision: A qualitative study on information literacy practices in midwifery counselling about contraceptives at youth centres in Southern Sweden. Information Research, 16(1), paper 466. Available at http:// InformationR.net/ir/16-1/paper466.html

Rivano-Eckerdal, J. (2011b). Young women choosing contraceptives: Stories about information literacy practices related to evaluation and use of information sources. Dansk Biblioteksforskning årg, 7(2/3), $19-31$.

Rivano-Eckerdal, J. (2012). Information sources at play: The appartus of knowledge production in contraceptive counseling. Journal of Documentation, 68(3), 278-298.

Rubin, H.J., \& Rubin, I.S. (2005). Qualitative interviewing: The art of hearing data (3rd ed.). Los Angeles: Sage Publications.

Ryan, R.M. (1995). Psychological Needs and the facilitation of integrative processes. Journal of Personality, 63(3), 397-427.

Ryan, R.M., \& Deci, E.L. (2000). The darker and brighter side of human existence: Basic psychological needs as a unifying concept. Psychological Inquiry, 11(4), 319-338.

Salander, P. (2002). Bad news from the patient's perspective: An analysis of the written narratives of newly diagnosed cancer patients. Social Science and Medicine, 55(5), 721-732.
Saracevic, T. (2007). Relevance: A review of the literature and a framework for thinking on the notion in information science. Journal of the American Society for Information Science and Technology, 58(13), 21262144.

Savolainen, R. (2006). Information use as gap-bridging: The viewpoint of sense-making methodology. Journal of the American Society for Information Science and Technology, 57(8), 1116-1125.

Savolainen, R. (2008). Everyday information practices: A social phenomenological perspective. Lanham: Scarecrow Press.

Savolainen, R. (2009). Information use and information processing: Comparison of conceptualizations. Journal of Documentation, 65(2), 187207.

Scheff, T.J. (2003). Shame in Self and Society. Symbolic Interaction, 26(2), $239-262$.

Scott, J., Treas, J., \& Richards, M. (Eds.). (2004). Blackwell companion to the sociology of families. Malden: Blackwell Publishing.

Shalin, D.N. (1986). Pragmatism and social interactionism. American Sociological Review, 51(1), 9-29.

Sheeran, P. (2002). Intention-behavior relations: A conceptual and empirical review. European Review of Social Psychology, 12(1), 1-36.

Sheldon, K.M., \& Bettencourt, B.A. (2002). Psychological needsatisfaction and subjective well-being within social groups. British Journal of Social Psychology, 41, 25-38.

Sheldon, K.M., \& Gunz, A. (2009). Psychological needs as basic motives, not just experiential requirements. Journal of Personality, 77(5), 14671492.

Sligo, F.X., \& Jameson, A.M. (2000). The knowledge-behavior gap in use of health information. Journal of the American Society for Information Science, 51(9), 858-869.

Somerville, M., \& Lloyd, A. (2006). Codified knowledge and embodied learning: The problem of safety training. Studies in Continuing Education, 28(3), 279-289.

Strauss, A.L., Fagerhaugh, S., Suczek, B., \& Wiener, C. (1997). Social organization of medical work. New Brunswick: Transaction Publishers.

Strauss, A.L., \& Corbin, J. (1998). Basics of qualitative research: Techniques and procedures for developing grounded theory. Thousand Oaks, CA: Sage.

Sullivan, K.T., \& Davila, J. (2010). Support processes in intimate relationships. New York: Oxford University Press.

Sundin, O. (2003). Towards an understanding of symbolic aspects of professional information: An analysis of the nursing knowledge domain. Knowledge Organization, 30, 170-194.

Talja, S., Tuominen, K., \& Savolainen, R. (2005). "Isms" in information science: Constructivism, collectivism and constructionism. Journal of Documentation, 61(1), 79-101.

Tuominen, K., \& Savolainen, R. (1997). A social constructionist approach to the study of information use as discursive action. In P. Vakkari, R. Savolainen, \& B. Dervin (Eds.), Information seeking in context: Proceedings of an international conference on research in information needs, seeking and use in different contexts (pp. 81-96). London: Taylor Graham.

Tuominen, K., Savolainen, R., \& Talja, S. (2005). Information literacy as a socio-technical practice. Library Quarterly, 75(3), 329-345.

Veinot, T.C. (2009). Interactive acquisition and sharing: Understanding the dynamics of HIV/AIDS information networks. Journal of the American Society for Information Science, 60(11), 2313-2332.

Veinot, T.C. (2010). We have a lot of information to share with each other. Understanding the value of peer-based health information exchange. Information Research, 15(4). paper 452. Available at http:// informationr.net/ir/15-4/paper452.html

Veinot, T.C., \& Williams, K. (2012). Following the "community" thread from sociology to information behavior and informatics: Uncovering theoretical continuities and research opportunities. Journal of the American Society for Information Science and Technology, 63(5), 847-864.

Veinot, T.C., Kim, Y.-M., \& Meadowbrooke, C.C. (2011). Health information behavior in families: Supportive or irritating? Paper presented at the American Society for Information Science \& Technology (ASIS\&T) Conference, New Orleans, LA. 
Vryan, K.D., Adler, P.A., \& Adler, P. (2003). Identity. In L.T. Reynolds \& N.J. Herman Kinney (Eds.), Handbook of symbolic interactionism (pp. 367-390). Walnut Creek: AltaMira Press.

Washer, P., \& Joffe, H. (2006). The "hospital superbug": Social representations of MRSA. Social Science \& Medicine, 63, 2141-2152.

Wathen, C.N., Wyatt, S., \& Harris, R. (Eds.). (2008). Mediating health information: The go-betweens in a changing socio-technical landscape. Basingstoke: Macmillian.
Weigert, A.J., \& Gecas, V. (2003). Self. In L.T. Reynolds \& N.J. Herman Kinney (Eds.), Handbook of symbolic interactionism (pp. 267288). Walnut Creek: AltaMira Press.

Weston, K. (1991). Families we choose: Lesbians, gays, kinship. New York: Columbia University Press.

Wilson, P. (1983). Second-hand knowledge: An inquiry into cognitive authority. Westport: Greenwood Press. 